\title{
Más globalización, menos democracia
}

\author{
JOSÉ ANTONIO GIMBERNAT \\ Instituto de Filosofía. CSIC
}

\begin{abstract}
El concepto de globalización ha adquirido una actualidad y relevancia imparables, pues pretende definir comprensivamente la irrupción de una pluralidad de procesos que penetran todos los espacios sociales. Ulrich Beck ${ }^{1}$ convincentemente piensa que la novedad del fenómeno de la globalización y sus efectos nos obliga a constatar una cesura histórica. Consecuentemente propone denominar a los resultados vigentes de estos procesos, segunda modernidad, como contradistinta de la anterior. Especialmente diferente en la relación distinta que en ella se induce entre economia y política.
\end{abstract}

La globalización introduce lógicas inéditas en el ámbito de las comunicaciones, en las formas de impactar a la opinión pública, en la economía y en la política, con nuevas configuraciones en el tejido social. Todas esas esferas no son reductibles entre sí; no son un juego de espejos, ni una reproducción automática, pero si congruentemente son interdependientes.

En este proceso adquiere una nueva dimensión la actividad comercial en su órbita transnacional. Se desenvuelve en un entramado de mutuas dependencias y reciprocas obligaciones. La globalización capilarmente se introduce por todos los poros de la vida. Los ciudadanos han tomado conciencia de los efectos en sus vidas de la transnacionalidad. Impregna sus hábitos de consumo, turismo; está presente y actúa en los medios de comunicación. No cabe duda de que sus efectos más importantes y novedosos se encuentran en las nuevas relaciones creadas entre capital y trabajo. $\mathrm{La}$ actividad industrial y financiera se deslocaliza. Esto es, su ámbito se hace transnacional. Y la nacionalidad del capital empresarial de carácter multinacional no coincide con la localización de sus empresas, ni con la nacionalidad de sus trabajadores. La industria de la cultura ha acentuado sus rasgos globales. Hoy es de dominio público la globalización de los riesgos ecológicos. En el espacio político se multiplican los actores transnacionales, con sus correspondiente instituciones y tratados. $Y$ también se han hecho cualitativamente diferente la concentración y acumulación del poder económico, cuyos centros más potentes se ramifican globalmente.

Frente esta nueva dimensión global sobre todo de la economía, las actuales sociedades carecen de Estado y de gobiernos mundiales, lo que ha propiciado un capitalismo todopoderoso, omnipresente y desorganizado, debido a lo endeble o a la ausencia de instancia políticas reguladoras.

Beck $^{2}$ señala las siguientes razones que destacan el profundo calado de la globa- 
lización, que se define como fenómeno nuevo e irrebasable:

a) la creciente interacción del comercio internacional junto al entramado global del mercado internacional y el creciente poder de las empresas transnacionales,

b) la permanente revolución de la tecnología de la información y de la comunicación,

c) la universalización del discurso de los derechos humanos, y consecuentemente, al menos retóricamente, la extensión del principio democrático,

d) el diluvio incontenible de imágenes, proporcionadas por la industria multinacional de la cultura,

e) la política internacional policéntrica. Junto a los gobiernos, se nos visualiza el poder creciente de los actores económicos transnacionales,

f) la pobreza tiene hoy insoslayablemente un planteamiento mundial,

g) creciente destrucción global del medio ambiente,

h) el carácter transnacional de los conflictos locales.

La fascinación e imposición arrolladora de estos procesos ha inducido a que se apodere de ellos un potentísimo movimiento ideológico de impronta neoliberal, de efectos reduccionistas, por destacar de manera absorbente su dimensión económica. Se ha hecho el intérprete de su dinámica y desarrollo. Con afán dogmático y con mitología casi metafísica pretende definir la única lógica posible de la economía globalizada, que a la vez desborda, supera y obliga a las economías nacionales y determina el campo de actuación de los Estado singulares. La política económica, según sus propagandistas, es única e indivisible; solo queda obedecer sus designios, debido a la fuerza coactiva que le proporcionan los hechos económicos irreversibles y sin alternativas. El monetarismo (combate a la inflación, reducción del déficit público, políticas monetarias restringidas, flexibilidad laboral) se ha convertido en su canon. Es el marco al que deben ajustarse todas las economías nacionales, fortalecido por las instituciones y tratados internacionales, con el objetivo de que ningún Estado descarrile de sus parámetros, sea rico o pobre. El paradigma es una suerte de nuevo fundamentalismo del merca$\mathrm{do}^{3}$. Mal aventurados aquellos gobernantes que no sigan estas directrices. Hans Tiermeyer, cuando era presidente del Bundesbank, así lo afirmaba: "Los mercados los sancionarán de inmediato, puesto que los políticos se encuentran ya bajo el control de los mercados financieros"4.

Y para estar presentes en ellos de manera competitiva, se requiere recortar los gastos del Estado, abandonando el mal llamado Estado providencia, limitar los derechos de los trabajadores, reducción de los gastos sociales, a la vez que se bajan los costos salariales, lo que suele finalizar en la permanente congelación real de estos salarios.

Los capitales extranjeros, que es indispensable atraer con el fin de producir riqueza e insuflar mercados boyantes, se ven cortejados en una carrera de los países para disminuir los impuestos de sus beneficios y mediante plurales fórmulas son subvencionadas las inversiones industriales. Pero además, en la actualidad, las grandes firmas pueden trasladar el grueso de sus beneficios a empresas filiales, localizadas en países que pujan entre sí con impuestos cada vez más recortados. Así en la gran paradoja neoliberal, a la vez que se incrementan los beneficios de las transnacionales, desciende $o$ incluso se elude la financiación por su parte de los gastos del Estado. Esta dictadura y radicalismo del nuevo mercado mundial, debilita consecuentemente la existencia del Estado social, uno de los logros en la mejor práctica de la justicia y en la redistribución de los bienes colectivos de los Estados democráticos occidentales, construidos de nueva 
planta tras la segunda guerra mundial. No hay ningún rebozo en declarar que este debilitamiento es el objetivo deseado. "El Estado de bienestar inflige un daño enormemente destructivo a sus supuestos beneficiarios... debilita el espíritu emprendedor y valiente de los individuos... coloca una carga de profundidad de resentimiento explosivo bajo los fundamentos de nuestra sociedad libre" $"$.

Como colofón y aspiración última se vislumbra lo que se ha llamado capitalismo sin trabajo ${ }^{6}$. Pues los costes totales del trabajo remunerado se han convertido en enemigo principal de las ganancias. Cuando las grandes transnacionales, a través del desarrollo espectacular de las nuevas tecnologías, consiguen reducir drásticamente numerosos puestos de trabajo, sus acciones tras tan buena nueva, se disparan al alza en las bolsas mundiales.

En último termino, el gran sueño es un capitalismo sin Estado, en donde el mercado dicta lo que es verdadero, bello, bueno y justo. Es la nueva Tabla de la Ley que exige reverencia. El 26 de Febrero de 1996 el semanario norteamericano Newsweek refería que la docena de las mayores empresas transnacionales había ahorrado en pocos años 360.000 puestos de trabajo. El hecho mereció el calificativo de killer capitalism. "Hace algún tiempo los despidos numerosos eran una infamia. Hoy cuanto más numerosos, más contenta la bolsa"7. El mismo fenómeno era denunciado por el semanario alemán Der Spiegel (12/1997) utilizando la expresión, Jobkiller

En este escenario, donde el mercado gobierna y los gobiernos gestionan ${ }^{8}$, los poderes públicos velan por que se cumpla el cuadro macroeconómico, fijado por los Bancos supranacionales. Su acción queda supeditada al imperio de la nueva economía y a crear las condiciones óptimas para los mercados. Esta subordinación de la política económica, que hace a los gobiernos subalternos de las instituciones finan- cieras, debilita la legitimidad democrática de las políticas económicas. Con razón Oskar Lafontaine denuncia esta preeminencia como una comprensión predemocrática de la política monetaria. Los bancos centrales se inmiscuyen en la política presupuestaria, de impuestos, sociales, salariales, mientras los gobiernos que pretenden variar las decisiones emanadas de estas instancias quedan anatematizados por una especie de "comunidad de fe" de los rectores económicos y empresariales ${ }^{9}$. En este marco, la democracia y el Estado social se sitúan a la defensiva. La democracia contemporánea que tenía su base y adquiría su legitimidad en la sociedad del trabajo, experimenta la conmoción de sus cimientos.

El paradigma dominante del mercado impone una triada sorprendente y desigual.

a) Beneficios empresariales de dos dígitos, al alza creciente.

b) Un capital financiero especulativo que vive una reedición más sofisticada de las antiguas "fiebres del oro" en los mercados mundiales, donde se ofrecen duros a pesetas, en los que se aspira a ganancias cercanas a los tres dígitos.

c) Si se compara con las pretensiones a) y b) resulta absurda por ausencia de equidad elemental y por cercenar las aspiraciones legitimas, la exigencia como tercer factor de la permanente moderación salarial (en el mejor de los casos estancamiento), tanto en época de crisis como en la de bonanza económica.

$\mathrm{El}$ argumento que defiende este marco retributivo resalta que de los tres componentes lo único maléfico para el sistema son las alzas salariales. Los propagandistas de esta ley de hierro mediante sus persistentes mensajes de "expertos", de resonancia única en los medios de comunicación, han conseguido que los asalariados internalicen el mencionado reparto. Solo la resignación puede impulsar a que se 
acepte esta especie de contrato social de rasgos leoninos por parte de unos ciudadanos que han empezado a considerar su puesto de trabajo como un premio otorgado, en vez de como un derecho.

\section{EL DEBATE ACTUAL DE LOS DERECHOS HUMANOS ${ }^{\circ}$}

En este escenario global economicista, los derechos humanos han padecido una lectura sesgada. Selectivamente se ha impuesto una interpretación liberal, en contra de las tesis que los delegados de los países occidentales defienden en los foros internacionales, que tiende a separar los derechos políticos y civiles, como derechos humanos por antonomasia, de los derechos económicos sociales y culturales, a los que se otorga un carácter aleatorio y desiderativo.

Hoy percibimos la quiebra y debilidad de las ideologías y conocemos que las grandes religiones, sin menospreciar su gran impacto cualitativo y numérico, significan actitudes y creencias no compartidas universalmente.

Constatamos que el único lenguaje universal que perdura como marco de diálogo mundial es el de los derechos humanos. En contra de los supuestos de los filósofos posmodernos, que pretenden haber asistido al sepelio de las convicciones morales de carácter universal, contenidas en los grandes relatos, sin embargo en la época de la globalización perdura la necesidad de encarar los graves problemas de la humanidad, -en los que ni más ni menos les va la vida- con respuestas que permitan acuerdos universales. Por ejemplo, en lo que se refiere a la desigual distribución de la riqueza y la pobreza, con sectores cada vez más amplios de la población mundial que no despegan en su anhelo por satisfacer sus necesidades de desarrollo económico y humano, con riesgos impre- decibles para la estabilidad mundial, como lo demuestra el desordenado proceso de inmigración del Sur hacia el Norte. También acerca de la cuestión de la paz y la guerra, cuando disponemos de armas que proliferan, capaces de llevar a la autodestrucción del mundo que conocemos. Además, los desequilibrios ecológicos que pueden llevar a la especie humana al borde de la extinción. Todo ello requiere un dialogo de dimensiones planetarias, que hoy sólo es posible abordar dentro del único referente universal que ofrece el lenguaje de los derechos humanos. La Declaración de 1948 representa el esfuerzo de los Estados, salidos de la Segunda Guerra Mundial, de dotarse de principios que ulteriormente inspiraron doctrina y códigos jurídicos capaces de evitar una repetición de lo acontecido. La Declaración consta de dos grandes capítulos, a lo largo de sus 30 artículos. El primero enuncia los derechos a las libertades individuales y los derechos de carácter cívico. El segundo refiere los derechos económicos, sociales y culturales de todos los ciudadanos de cualquier Estado.

Un teórico actual de los derechos humanos, Antonio Cassese ${ }^{1 \mathrm{I}}$, resume el contenido de la Declaración de 1948 en cinco puntos.

1.- Los derechos de la persona (derecho a la igualdad, a la vida, a la libertad, a la seguridad).

2.- Los derechos que corresponden al individuo en sus relaciones con los grupos sociales de los que forme parte (derecho a la intimidad en la vida familiar, a la libertad de movimiento de las personas, a la propiedad, a la libertad religiosa).

3.- Derechos políticos (libertad de pensamiento y reunión, derecho electoral activo y pasivo, derecho a tener acceso al gobierno y a la administración de la cosa pública).

4.- Derechos económicos, sociales y culturales relacionados con el trabajo y la 
producción y referidos también a la educación (derecho al trabajo y a una justa retribución, derecho al descanso, derecho a la asistencia sanitaria, etc.).

5.- Derecho a una orden social internacional justo.

La Declaración debe entenderse como un compromiso entre los valores de la concepción occidental de la democracia, la reivindicación de los Estados socialistas de carácter igualitario y las aspiraciones de los países del tercer mundo a obtener niveles económicos aceptables, como condición para un asentamiento verosimil de las garantías de todos los derechos humanos. Pretende constituirse en un decálogo para seis mil millones de personas. Pactos internacionales ulteriores han buscado dotar de fuerza vinculante a los derechos humanos, que deberian así ser respetados por todos los Estados. Por su medio los países del tercer mundo han logrado que se reconozca el derecho a la autodeterminación y la soberanía como un derecho colectivo. Posteriormente también se ha considerado como derecho de los pueblos el derecho al desarrollo.

Los nuevos movimientos sociales que han adquirido carta de naturaleza en la posguerra se han convertido en modernos portadores de nuevos valores, que han ido acotando espacios para nuevos derechos, que se han llamado de la tercera generación, tras la de los civiles y la de los sociales. Se han afirmado de este modo el derecho a la paz y a la objeción de conciencia, defendidos por el movimiento pacifista, se ha reivindicado la igualdad de la mujer y el derecho de la humanidad a la preservación del medio ambiente, frente a imperativos industriales, que causan su creciente déterioro, con daños de efectos irreversibles.

La aceptación mundial de la Declaración de los Derechos Humanos, es hoy punto de referencia, para enjuiciar la realidad política y social de los Estados. Ello les ha ido dotando de gran relevancia internacional y de una gran proyección política. Son por tanto instrumento de denuncia de unos Estados con respecto a otros. También es el texto que se aduce como autojustificación de las propias leyes y prácticas políticas y sociales. Este relieve en la comunidad internacional convierte su referencia en una tentación para instrumentalizarlos por razones políticas en beneficios propio y para descalificar al adversario. Pueden así verse degradados como arma arrojadiza, que se dispara oportunistamente. Así sucedía habitualmente en los foros internacionales cuando el mundo estaba dividido en dos bloques. Entonces Occidente, con razón insistía en las conculcaciones de los derechos civiles y políticos en los países del bloque comunista. Estos a su vez denunciaban el olvido y la responsabilidad del primer mundo en lo que respecta a los derechos económicos y sociales. Subrayando el papel de estos como antiguas potencias coloniales en la depredación efectuada en sus antiguas colonias, posteriormente incapaces de surgir por sí mismas de su postración. Hoy el debate se ha desplazado a otras coordinadas geográficas: Norte-Sur. El Norte continua escuchando las denuncias de sus oponentes por las prácticas económicas y financieras que imponen en la economía globalizada y que son definidas por sus adversarios como neocoloniales, prosiguiendo el colonialismo económico practicado en el siglo $\mathrm{XX}$ por las naciones más poderosas. De hecho la razón de ser de esta nueva polarización está más que justificada, debido a que, aun siendo muchas y horribles las violaciones de los derechos políticos y civiles, la mayor violación de los derechos humanos, incrementada ferozmente en las últimas décadas, deriva en la extensión irrefrenable de la pobreza. Directa o indirectamente su creciente dimensión se opone a las angustiadas expectativas de grandes sectores de la humanidad, que esperan que se convier- 
tan para ellos en realidad tangible los derechos económicos, sociales y culturales, cuya protección es pomposamente reclamada en las declaraciones públicas y pactos internacionales. Además en situaciones en que las condiciones materiales y culturales son tan precarias, propias de niveles de miseria, difícilmente puede prosperar el ejercicio consciente y autónomo de los derechos civiles y políticos.

En los encuentros internacionales un importante grupo de Estados, acompañados beligerantemente por el gran movimiento moderno de los derechos humanos, destacan la desatención y olvido de los derechos de la segunda generación. Junto a estas aspiraciones, el llamado derecho al desarrollo se encuentra en la práctica en un inquietante y profundo retroceso. Las políticas de cooperación, aún en aquellos logros bien intencionados y que no recubren finalidades neocoloniales, en sus grandes metas, después de tres décadas hay que darlas por fracasadas. Las políticas de ajuste estructural, impuestas a los países no desarrollados, más allá de su coherencia macroeconomica, han conducido a un mayor empobrecimiento de la mayor parte de los ciudadanos de estos países de escasos recursos. Las consecuencias han sido una drástica disminución de las inversiones tanto en infraestructuras como en proyectos y gastos sociales de Estados empobrecidos por el peso de la deuda externa. Los planes impuestos han dejado a los Estados con menores recursos y, en consecuencia, sus ciudadanos ven vulnerados sin remedio sus derechos económicos sociales y culturales. La eliminación de la deuda externa, la reducción sustancial de los gastos militares y un nuevo planteamiento de la cooperación económica, en lugar de la orientación fracasada son requisitos exigibles para un mayor fortalecimiento de la practica de los derechos humanos. Pero es evidente que estas propuestas están muy lejos de las prioridades y expectativas de la nueva económica. Baste recordar que al prin- cipio de la década de los años setenta Naciones Unidas denunciaba la desigualdad inherente al orden económico internacional, defendiendo reformas profundas en favor del desarrollo. Un tanto simbólicamente como muestra del cambio de actitud, solicitaron de los países desarrollados que dedicasen el 0'7\% del PIB para la cooperación al desarrollo. La comunidad internacional hizo oídos sordos al llamamiento. $Y$ además las cifras -mucho menor que la propuesta- en torno al $2 \%$ contabilizaba como ayuda al desarrollo, venta de armamentos y transacciones comerciales que con frecuencia han revertido más en beneficio de las propias economías que en las "ayudadas". Así treinta años después, la dejación de estas recomendaciones para cambiar el signo de la cooperación amenaza con ser castigada con flujos migratorios de problemática asimilación. Se puede apreciar por lo expuesto que existe una dura confrontación entre las exigencias de los dos grandes capítulos de la Declaración de los derechos humanos, sus posibles primacías y subordinaciones. Ello confluye en el debate sobre su carácter universal, sobre su indivisibilidad y la interdependencia entre los derechos de carácter civil y los de impronta social. Teóricamente en los países occidentales ha madurado una doctrina acerca de estas cuestiones que básicamente es acertada. Se afirma el carácter universal de los derechos humanos, esto es, todos los derechos tienen que verse cumplidos y garantizados, más allá de todo tipo de diferencias culturales, sociales, religiosas e ideológicas. Además se postula el carácter indivisible de las dos grandes secciones de la Declaración. Esto es, configuran una totalidad con interdependencia de todos sus componentes que no es licito desgajar. Esta doctrina zanja en el nivel de las ideas en gran parte la confrontación entre distintas percepciones, pero lamentablemente sólo en ese nivel. De hecho, en la prác tica política de los países desarrollados, 
domina las versiones liberales, que seleccionan privilegiando tan sólo alguno de los derechos civiles, cuando se disponen a definir su política internacional, y según este criterio parcial, conceden o niegan el aval en derechos humanos a otros países. Dentro de esta parcialidad se disimulan como lunares menores de países amigos no desarrollados la corrupción y hasta la parálisis de las instituciones democráticas, la persecución del disidente, corroborada por la práctica impunidad con la que actúan los agentes represivos. Y en esta consideración no se tiene adecuadamente en cuenta -por juzgarlas inevitables- las condiciones materiales de la mayoría de la población; lo cual significa desatender sus justas pretensiones de acceder a los derechos de carácter económico, social y cultura. En realidad en esta sesgada interpretación, se tiende a estimar que propiamente sólo son derechos humanos, los de componente civil y político. Y ello por una doble razón los derechos de pretensión social no son susceptibles de reclamación individual en los códigos nacionales, al menos en su mayoría. Piénsese en el derecho al trabajo a la vivienda, a la alimentación, a una digna asistencia sanitaria, etc. La segunda razón la encontramos en la incapacidad real y actual de los Estados para garantizar tales derecho a miles de millones de ciudadanos. En la práctica, en la política de los Estados occidentales, tanto en su interior como, sobre todo, con respecto a los países no desarrollados, los derechos humanos -en contra de las tesis sostenidas- son divisibles y en consecuencia tan poco son vistos como universales, mas allá de la buena intención de la afirmación que así lo sostiene.

\section{GLOBALIZACION VERSUS DERECHOS HUMANOS}

En la mentalidad que corresponde a los imperativos de la nueva economía, los derechos humanos, sobre todo en su faz de derechos económicos sociales y culturales, deben subordinarse a los imperativos del mercado y de la competencia mundial. El derecho al desarrollo, los derechos al trabajo, a la salud, a la alimentación, a la seguridad social, a las pensiones, al seguro de desempleo, a la cultura, como igualmente los derechos ecológicos son un buen deseo que el orden económico internacional y sus leyes no permiten que sean efectivos para $2 / 3$ de la humanidad. Ya sea con resignación o cinismo se constata que la economía globalizada ahora establecida no da para más. Pero la aceptación de esta limitación no permite cuestionar dicho orden, porque es inalterable y carecemos de otro disponible.

Habitamos un orbe en el que las grandes transnacionales contratan a sus empleados por ordenadores, estos trabajan por todo el mundo, en su domicilio, con su ordenador y son fulminantemente despedidos por ordenador ${ }^{12}$. Se encuentran a la intemperie en relación a todo lo que han sido los avances sociales, plasmados, en la práctica de los convenios laborales, en la seguridad frente al desempleo, la consideración social y redistributiva del salario, en general de los grandes avances de los derechos de los trabajadores ${ }^{13}$.

En este horizonte, se afirma ya abiertamente que en el futuro el $20 \%$ de la población mundial será suficiente para mantener la economía que imparablemente se globaliza. Es la horrible visión de un futuro de capitalismo sin trabajo. Su lema hobbessiano es to have lunch or to be lunch. Quienes preveen este futuro, estiman que hemos entrado en una senda de racionalización de la industria que discurre por los caminos que hace décadas emprendió la agricultura, en lo referente a lo superfluo de la mayoría de la mano de obra. Como consecuencia, la protección que significaba el Estado social tiene fecha de caducidad y no podrá erigirse en los países no 
desarrollados. Esta auténtica contrarreforma de los derechos sociales pretende mostrarse como un fenómeno natural. $\mathrm{O}$ de manera más sutil, como la modernización contra la que no cabe rebelarse. Modernización entendida como la adaptación a las nuevas exigencias de la economía globalizada. El concepto se ha visto de nuevo reducido a categorías económicas. Modernidad es simplemente adaptación a las insoslayables exigencias de la nueva economía. Las cuestiones de cómo queremos organizar la vida en común, qué sociedad queremos, son cuestiones descalificadas como contramodernizadoras y en el mejor de los casos retóricas ${ }^{14}$.

Los defensores del sistema (casi todos los expertos), a pesar de todas las deficiencias señaladas, consideran que hemos entrado en un estadio superior de la economía, mediaticamente definido como turbo-capitalismo para designar plásticamente su acelerada velocidad y poderosísimo desarrollo. Para persuadir a los recalcitran tes, se insiste en que la competencia mundial no permite las veleidades sociales, que en otras épocas eran soportables, cuando el espacio dominante se ceñía al interior de las economías nacionales. La idea de la competencia se ha convertido en la coartada para bajar los salarios, para recortar los derechos de los trabajadores, y en último término es utilizada para chantajear las demandas laborales. Simplemente se amenaza con trasladar las industrias a países de bajos salarios. Innovación se convierte en enemigo de la justicia.

Ahora, pues, los mercados financieros son jueces y jurados de las decisiones económicas. Si los estados resisten, al final deberán pagar las facturas que les presenta la ley del mercado. Todo ello no se encuentra lejos del pronóstico de Karl Marx, que en otro contexto muy diferente proclamaba que "La tendencia general de la pro- ducción capitalista, consiste en no elevar los niveles medios de los salarios, sino en rebajarlos o presionar el valor del trabajo hasta sus limites mínimos" ${ }^{15}$. Ello antes de que el posterior capitalismo, en sus espacios más avanzados modificara dicha tendencia. El crecimiento exponencial de la riqueza en nuestro planeta se ha visto apropiado por minorias cada vez más reducidas, Las 255 mayores fortunas equivalen a los ingresos de los que disponen los dos mil quinientos millones de los ciudadanos más pobres del planeta. Las diferencias y fosas entre riqueza y pobreza se agrandan, a pesar del crecimiento constante y multiplicador de los bienes producidos; el 25\% de los Estados disfruta del $84 \%$ del producto social mundial. Desde 1960 se ha doblado la diferencia entre la riqueza del $25 \%$ de los países más ricos con respecto a la misma proporción de los más pobres.

La modernidad económica, en conclusión, debilita la democracia, al situarse por encima de las instituciones políticas a las que convierte en subalternas. La desregulación de los mercados interiores e internacionales permite la acumulación brutal de la riqueza, que tiene como contrapartida la extensión inhumana de la pobreza. La ley del más fuerte económicamente controla los mercados mundiales, que sé pretenden neutrales. El planeta esta poblado por cerca de mil millones de hambrientos. Todo ello hace que en esas condiciones los derechos humanos, que declamatoriamente se han convertido en el código de la conducta de la humanidad, en realidad estén en retirada. Las democracias son rehenes de los poderes económicos que nadie ha elegido, ni legitimado democráticamente. El gran capítulo de los derechos económicos, sociales y culturales, en su dimensión globalizada, todavía esta inédito. 


\section{NOTAS}

' U. Beck, Was ist Globalisierung?, Frankfurt, Suhrkamp,1998

2 Ibid, 29

${ }^{3}$ A. Giddens, La tercera vía, Madrid, Taurus, 1998. pp. 173 y ss.

4 Citado por I. Ramonet, Geopolitique du chaos, Paris, Gallimard, 1999, p. 85.

${ }^{5}$ D. Marsland, Welfare or Welfare State? Basingstoke, Macmillan, 1996, p. 212 (citado por A. Giddens, op. cit.., .p. 24).

${ }^{6}$ Cfr. U. Beck, op. cit., pp. 105-114

${ }^{7}$ H-P. Martin, H. Schumann, Die Globalisierungsfalle, Munich, Rowohlt, 1996.

8 I. Ramonet, op. cit., p. 101.

${ }^{9}$ O. Lafontaine, Das Herz schlägt links, Munich,
Econ, 1999, pp. 55-56. Cfr. También O. Lafontaine, C.Müller, Keine Angst vor der Globalisierung, Bonn, Dietz,1998.

${ }^{10} \mathrm{Cfr}$. J.A. Gimbernat, Los derechos Humanos. A los cincuenta años de la Declaración de 1948, Cuadernos Fy S, Santander, Sal Terrae, 1998.

1 A Cassese, Los derechos humanos en el mundo contemporáneo, Barcelona, Ariel,1991, pp. 46-48.

12 H-P. Martin, H. Schumann. op. cit., p 11.

${ }^{13}$ Cfr. B. Friot, Puissances du salariat, La Dispute, 1997 y R. Sobel, "Demain, le salariat", Les Temps modernes, 54 année, n.603, pp. 57-69.

O.Lafontaine, op. cit. pp 64-65.

${ }^{5}$ K.Marx/F.Engels, Werke, T.16, "Lohn, Preis und Profit", Berlin, 1962, pp.103-152. 